\title{
A retrospective study of post-partum intrauterine contraceptive devices in a government maternity home of Delhi
}

\author{
Neha Taneja ${ }^{1}$, Sujata Gupta ${ }^{2 *}$, Karuna N. Kaur $^{1}$
}

\begin{abstract}
${ }^{1}$ Laboratory of Disease Dynamics and Molecular Epidemiology, Laboratory of Health Data Analytics and Visualization Environment, Amity Institute of Public Health, Amity University, Noida, Uttar Pradesh, India

${ }^{2}$ North DMC Medical College and Hindu Rao Hospital, Delhi, India
\end{abstract}

Received: 02 August 2020

Accepted: 16 September 2020

\author{
*Correspondence: \\ Dr. Sujata Gupta, \\ E-mail: sujata080583@gmail.com
}

Copyright: (C) the author(s), publisher and licensee Medip Academy. This is an open-access article distributed under the terms of the Creative Commons Attribution Non-Commercial License, which permits unrestricted non-commercial use, distribution, and reproduction in any medium, provided the original work is properly cited.

\begin{abstract}
Background: Post-partum period is defined to be an ideal time for family planning counselling. Being a second largest populated country, India has a high rate of unintended pregnancy especially in post- partum women. There is a need for accessible, reliable contraception like post-partum intra uterine contraceptive device (PPIUCD) in our country. The present study is an attempt to evaluate the safety and efficacy of intra- uterine devices in post-partum women.

Methods: The study population included all the women who delivered vaginally who were counselled for PPIUCD insertion in prenatal period, early labour and within 48 hours of delivery and were willing to participate in the study. Participants were interviewed prior to discharge after receiving a PPIUCD and then six, ten, fourteen weeks and 6 months or earlier when necessary. Institutional ethical approval and informed consent were taken.

Results: A total of 1625 deliveries took place out of which only 888 were inserted PPIUCD. So, the total acceptance rate was $54.6 \%$. Majority of cases were between the age group of 21-25 (46.4\%) and most of them were primipara (39.8\%). 34.8\% came for routine follow up in OPD at 6 weeks, $14 \%$ at 6 months and $6.1 \%$ at 1 year.

Conclusions: The IUCD insertion has been proved to be a safe and effective method of contraceptive with very few side effects and no major complications. To increase the knowledge and skills among health care providers, it is necessary to arrange training on PPIUCD.
\end{abstract}

Keywords: PPIUCD, Contraceptive, Post-partum

\section{INTRODUCTION}

Unmet needs for contraception have been a major hurdle to achieve desirable family planning goals in India. According to national family health survey (NFHS) 4 data, the contraceptive prevalence rate in India is $56.3 \%$ and more than $40 \%$ of the couples are not using any method of contraception. ${ }^{1}$ Family planning if effectively accepted can avert nearly one-third of maternal deaths and $10 \%$ of child mortality when couples space their pregnancies more than two years apart. ${ }^{1}$ Short intervals between births are linked with higher maternal and child mortality and morbidity. ${ }^{2}$
Postpartum period is a highly vulnerable period for unintended pregnancy as there are limited contraceptive options for breastfeeding mothers. Immediate postpartum is the ideal time to begin contraception as women in this period are more receptive to the family planning advice. Postpartum family planning (PPFP) is the prevention of unintended and closely spaced pregnancies through the first twelve months following childbirth. ${ }^{1}$ Postpartum women need a range of effective contraceptive methods to be able to prevent an unplanned pregnancy, within a short interval. ${ }^{1,3}$ 
A 2010 Cochrane review concluded that PPIUCDs were a safe and effective contraceptive method. The public health benefits from PPIUCDs stemmed from the women's increased accessibility to PPIUCDs following facility births, as PPIUCDs could be offered at health facilities after childbirth. This, in turn, decreased opportunity and other costs incurred by clients who may otherwise have to return to facilities to access contraceptive services. $^{4}$

According to NHF-4, In India $78.9 \%$ of deliveries are institutional delivery. ${ }^{5}$ With increasing numbers of women electing to give birth in health institutions, the government of India decided to strengthen PPFP and introduced PPIUCD services in a phased manner. The provision of PPIUCDs is being rapidly scaled up in India.

The government of India is promoting Institutional deliveries through programmes like janani suraksha yojna (JSY). This programme scheme has increased the institutional deliveries rate and postpartum care in government hospitals. Hence It gives the health care providers an opportunity to counsel women regarding PPIUCD insertion. ${ }^{6}$

Due to dearth of research in government hospitals regarding PPIUCD insertion. Thus, the present study was planned to describe the experience of immediate postpartum IUCD in women delivering vaginally in a government maternity home. This stimulated us to analyse the PPIUCD insertions at the institute.

Through this study we aim to determine the demographic characteristics and perception and satisfaction of women with PPIUCDs, and complications that occurred after insertion of PPIUCDs. The overarching aims of this study were to inform the stakeholders about the experience of the PPIUCD program in the country and provide guidance for further scaling up of the PPIUCD program in India.

\section{METHODS}

Women aged 15-39 years, who received PPIUCDs in government maternity home of Delhi were participated during April 2015 to March 2017.

Inclusion criteria included women who were willing to give consent for study and who delivered vaginally who were counselled for PPIUCD insertion in pre-natal period, early labour and within 48 hours of delivery.

All the women who delivered vaginally and ready for PPIUCD insertion during the study period were included in the study. So out of 1625 women who delivered vaginally, 888 women were meeting the criteria and thus were taken in the study. Data was collected from participants using a structured questionnaire. A record of follow up was maintained at the post-partum clinic. A telephonic follow up was done when a clinic visit was not feasible or to report symptoms, expulsion of IUCD or at the convenience of the client. Participants were interviewed prior to discharge after receiving a PPIUCD and then six, ten, fourteen weeks and 6 months or earlier when necessary.

The insertion of PPIUCD was done by skilled obstetricians under asepsis after informed consent. The standard infection prevention protocols were followed. The quality of PPIUCD services provided at the centre were assessed and monitored as per the performance standards for immediate PPIUCD counselling and services. After getting institutional ethical approval women were enrolled in the study. Informed consent was taken after telling them about study in local language.

Exclusion criteria excluded anaemia (haemoglobin $<10$ $\mathrm{g} / \mathrm{dl}$ ), PPH, with premature rupture of membranes $>18$ hours, obstructed labour, fibroid, congenital malformation of uterus, active STD, lower genital tract infection and allergy to copper.

Data was entered into MS-excel sheet and were analyzed with SPSS V21 Software.

\section{RESULTS}

A total of 1625 deliveries took place from $1^{\text {st }}$ April 2015 to $31^{\text {st }}$ March 2017 out of which only 888 were inserted PPIUCD. So, the total acceptance rate was $54.6 \%$ (Table 1) shows the demographic characteristics of clients. Majority of cases were between the age group of 21-25 $(46.4 \%)$ and most of them were primipara (39.8\%).

Out of 888 , only $34.8 \%$ came for routine follow up in OPD at 6 weeks, $14 \%$ at 6 months and $6.1 \%$ at 1 year as shown in (Table 2). During $1^{\text {st }} 6$ weeks, 221 were telephonically asked for their experience with PPIUCD and 24 were lost to follow up. In PPIUCD recipient's expulsion was most commonly reported in $10.7 \%$ of clients. There were no cases of perforation or any other major complication. PPIUCD had no effect on lactation. There were 39 clients who came for removal of PPIUCD. Common cause for removal was pain in abdomen.

Table 1: Baseline socio-demographic and obstetric profile of women.

\begin{tabular}{|ll|}
\hline Age (year) & $\mathbf{N}(\%)$ \\
\hline $15-20$ & $79(8.9)$ \\
\hline $21-25$ & $412(46.4)$ \\
\hline $26-30$ & $289(32.5)$ \\
\hline $31-35$ & $86(9.6)$ \\
\hline$>=36$ & $22(2.5)$ \\
\hline Parity & \\
\hline Primipara & $354(39.8)$ \\
\hline Para-2 & $324(36.5)$ \\
\hline Para-3 & $171(19.3)$ \\
\hline para $>=4$ & $39(4.4)$ \\
\hline
\end{tabular}


As shown in table $1.46 .4 \%$ of cases were between the age group of 21-25 years followed by $32.5 \%$ in 26-30 years. Majority of women were primipara $(39.8 \%)$.

Table 2 depicts the follow up details of clients; $34.8 \%$ women were able to complete follow up within 6 weeks whereas only $6.1 \%$ were able to complete 1 year.

Table 2: Follow up details of clients.

\begin{tabular}{|c|c|c|c|}
\hline $\begin{array}{l}\text { Total } \\
\text { PPIUCD } \\
\text { inserted }\end{array}$ & $\begin{array}{l}\text { Follow-up } \\
\text { within } 6 \\
\text { weeks }(\%)\end{array}$ & $\begin{array}{l}\text { Follow-up } \\
\text { at } 6 \text { month } \\
(\%)\end{array}$ & $\begin{array}{l}\text { Follow- } \\
\text { up at } 1 \\
\text { year }(\%)\end{array}$ \\
\hline 888 & $306(34.8)$ & $124(14)$ & $54(6.1)$ \\
\hline
\end{tabular}

Table 3, reported that most common complication among clients at 6 weeks was expulsion $(10.7 \%)$ followed by removal $(9.9 \%)$ and pain $(7.1 \%)$.

Table 3: Complications among the clients at 6 weeks.

\begin{tabular}{|ll|}
\hline Complains & N $(\%)$ \\
\hline Expulsion & $95(10.7)$ \\
\hline Bleeding & $43(4.8)$ \\
\hline Pain & $63(7.1)$ \\
\hline Removal & $88(9.9)$ \\
\hline Infection & $31(3.5)$ \\
\hline
\end{tabular}

Table 4, shows that failure rate of PPIUCD were seen in only $0.3 \%$ of the women.

\section{Table 4: Failure rate of PPIUCD (pregnancy with} PPIUCD in-situ) in the study.

\begin{tabular}{|ll|}
\hline Failure rate of PPIUCD & N $(\%)$ \\
\hline Pregnancy & $3(0.33)$ \\
\hline
\end{tabular}

In Table 5, pain abdomen (4.8\%) was one of the most common reason for removal followed by bleeding $(3.5 \%)$ and string problem $(0.76 \%)$.

Table 5: Reasons for removal.

\begin{tabular}{|l|l|}
\hline Reasons & N $(\%)$ \\
\hline Bleeding & $31(3.5)$ \\
\hline Pressure from family & $4(0.51)$ \\
\hline Pain abdomen & $43(4.8)$ \\
\hline String problem & $7(0.76)$ \\
\hline Wants tubal ligation & $3(0.335)$ \\
\hline
\end{tabular}

\section{DISCUSSION}

Out of all women who are present in the study, the total acceptance of 888 women were observed. Highest rate of acceptance was observed among age group of 21-25 years $(46.4 \%)$, which is comparable with other studies done by Katheki et al and Mishra whereas in a study by Maluchuru et al from Guntur, the highest rate of acceptance was among age group of 30-39 years $(27.67 \%) .^{12,13}$

In this study, the acceptance was higher in primipara $(39.8 \%)$ contrary observation was found in a study in North India, by Shukhla et al where the acceptance was higher in multipara $(68.33 \%){ }^{14}$

Studies by Grimes and Borthakur et al GMCH Assam also found higher acceptance among multipara. Goswami et al also found higher acceptance (48\%) among multipara, whereas Maluchuru, Mishra, Gautam and Vidyarama et al found a higher acceptance in primipara which were 15.42, 13.76, 71.91 and $15.47 \%$ respectively. ${ }^{12,13,15-19}$

Due to lack of knowledge and awareness most women in the community were not aware of the PPIUCD. In the present study most, women were counselled regarding PPIUCD during the postnatal period because it was only an opportunity to provide women with information about PPIUCD. The hospital being a government centre and the maximum number of women delivered in our hospital were for the first time. PPIUCD is a relatively new method of contraception in this community.

In this study the most common reason for removal is pain in the abdomen $(4.8 \%)$ followed by bleeding $(3.5 \%)$. Only $0.76 \%$ had removal due to string problems. Similarly, findings were reported in Maluchuru et al found bleeding $(27.27 \%)$ to be the most common reasons for removal. ${ }^{13}$ In this study, a higher rate of expulsion was observed about (10.7\%) when compared to other studies. Similar rate of expulsion of $10.7 \%$ by six months was reported in a study of 1317 women in north India. ${ }^{21}$ A rate of $5.6 \%$ expulsion was reported among 210 women in a clinic in Hubli, Karnataka state in India. ${ }^{20} \mathrm{~A}$ Higher expulsion rate of around $9-16 \%$ have been reported in some studies. ${ }^{23,24}$ Studies published in nineties and early 2000 reported rates of about $9-13 \% .^{7-9}$ However, lower expulsion rates have been reported more recently with improvements in insertion technique. ${ }^{10,11}$

There was no case of perforation and misplaced IUCD reported in our study. According to global health technical few reports addressing the relative safety of immediate post-partum insertion. ${ }^{24}$

Hence, PPIUCD was reported to be one of the safe and effective methods.

Follow up was found to be $34.8 \%$ within 6 weeks, $14 \%$ at 6 months and $6.1 \%$ at 1 year. These declined findings reported poor integration of vertical programs at all levels. The mindset of "insert, report and forget "needs to be changed by "counsel, report, insert, follow up and report". 


\section{CONCLUSION}

To conclude, this study found a good acceptance of PPIUCD among women participants. There was no case of Perforation reported. Thus, immediate postpartum IUCD insertion appears to be a safe and effective method of contraceptive with very few side effects and no major complications.

To improve the acceptance regarding PPIUCD, the community should be educated. Myths and fear associated with IUCD usage and public awareness regarding the concept of PPIUCD need to be improved. To increase the knowledge and skills among health care providers, it is necessary to arrange training on PPIUCD. This will further promote PPIUCD use and aid in reduction in the expulsion rate.

\section{Funding: No funding sources}

Conflict of interest: None declared

Ethical approval: The study was approved by the Institutional Ethics Committee

\section{REFERENCES}

1. Jairaj S, Dayyala S. A Cross Sectional Study on Acceptability and Safety of IUCD among Postpartum Mothers at Tertiary Care Hospital, Telangana. J Clin Diagn Res. 2016;10(1):LC01-4.

2. Rutstein SO. Effects of preceding birth intervals on neonatal, infant and under-five years mortality and nutritional status in developing countries: evidence from the demographic and health surveys. Int J Gynaecol Obstet. 2005;89(1):S7-24.

3. Kumar S, Sethi R, Balasubramaniam S, Charurat E, Lalchandani K, Semba R et al. Women's experience with postpartum intrauterine contraceptive device use in India. Reprod Health. 2014;11:32.

4. Grimes DA, Lopez LM, Schulz KF, Van Vliet HA, Stanwood NL. Cochrane Database Syst Rev. 2010;(5):CD003036.

5. Institutional Deliveries. (n.d.). Available from: https://niti.gov.in/content/institutional-deliveries. Accessed on 31 July, 2020.

6. Chi IC, Wilkens L, Rogers S. Expulsions in immediate postpartum insertions of Lippes Loop D and Copper $\mathrm{T}$ IUDs and their counterpart Delta devices--an epidemiological analysis. Contraception. 1985;32(2):119-34.

7. Tatum HJ, Beltran RS, Ramos R, Van Kets H, Sivin I, Schmidt FH. Immediate post placental insertion of GYNE-T 380 and GYNE-T 380 postpartum intrauterine contraceptive devices: randomized study. Am J Obstet Gynecol. 1996;175:1231-5.

8. Celen S, Möröy P, Sucak A, Aktulay A, Danisman N. Clinical outcomes of early post placental insertion of intrauterine contraceptive devices. Contraception. 2004;69:279-82.
9. Araujo VB, Ortiz L, Smith J. Postpartum IUD in Paraguay: a case series of 3000 cases. Contraception. 2012;86:173-86.

10. Blumenthal P, Shiliya N, Neukom J, Chilambwe J, Vwalika B, Prager B et al. Expulsion rates and satisfaction levels among immediate postpartum IUD users in peri-urban Lusaka, Zambia. Contraception. 2011;84:320.

11. Runjun D, Bornali P. A retrospective study on acceptability and complications of ppiucd insertion. J Evol Med Den Sci. 2016;5(31):1631-4.

12. Maluchuru S, Aruna V, Prabhavathi N. Postpartum intrauterine device insertion-2 years, experience at tertiary care center in Guntur medical college/Govt general hospital, Guntur. J den med sci. 2015;14(3):56-61.

13. Shukla M, Qureshi S, Chandrawati. Post-placental intrauterine device insertion-a five year experience at a tertiary care centre in north India. Indian $\mathbf{J}$ Med Res. 2012;136(3):432-5.

14. rimes DA, Lopez LM, Schulz KF, Van Vliet HA, Stanwood NL. Immediate post-partum insertion of intrauterine devices. Cochrane Database Syst Rev. 2010;(5):CD003036.

15. Borthakur S, Sarma AK, Alakananda, et al. Acceptance of postpartum intra-uterine contraceptive device (ppiucd) among women attending gauhati medical college and hospital (gmch) for delivery between January 2011 to December 2014 and their follow up. J Evol Med Den Sci. 2015;4(92):15756-8

16. Goswami G, Yadav K, Patel A. A prospective study to evaluate safety, efficacy and expulsion rate of post placental insertion of intra uterine device. J Evol Med Den Sci. 2015;4(56):9770-74.

17. Gautam R, Arya KN, Kharkwal S, Singh S, Trivedi M. Over view of immediate PPIUCD application in Bundelkhand region. J Evol Med Dent Sci. 2014;3(36):9518-26.

18. Vidyarama R, Nagamani T, Prasad K. PPIUCD as a long acting reversible contraceptive (larc)-an experience at a tertiary care centre. Int J Scie Res. 2015;4(5):5-7.

19. Kittur S, Kabadi YM. Enhancing contraceptive usage by post-placental intrauterine contraceptive devices (PPIUCD) insertion with evaluation of safety, efficacy, and expulsion. Int $\mathrm{J}$ Reprod Contracept Obstet Gynecol. 2012;1:26-32.

20. Bonilla Rosales F, Aguilar Zamudio M, Cázares Montero ML, Hernández Ortiz ME, Luna Ruiz MA. Factors de expulsión del dispositivo intrauterino TCu380A aplicado en puerperio inmediato y tardío [Factors for expulsion of intrauterine device TCu380A applied immediately postpartum and after a delayed period]. Rev Med Inst Mex Seguro Soc. 2005;43:5-10.

21. Celen S, Möröy P, Sucak A, Aktulay A, Danişman N. Clinical outcomes of early postplacental insertion of intrauterine contraceptive devices. Contraception. 2004;69(4):279-82. 
22. Shukla M, Qureshi S, Chandrawati. Post-placental intrauterine device insertion-a five year expérience at a tertiary care centre in north India. Indian $\mathrm{J}$ Med Res. 2012;136:432-5.

23. Sofat R. Postpartum CuT insertion - a trial. Indian J Maternal Child Health. 1990;1:23-4.
Cite this article as: Taneja N, Gupta S, Kaur KN. A retrospective study of post-partum intrauterine contraceptive devices in a government maternity home of Delhi. Int J Reprod Contracept Obstet Gynecol 2020;9:4932-6. 